Article

\title{
Development of Improved High-Performance Liquid Chromatography Method for the Determination of Residual Caprylic Acid in Formulations of Human Immunoglobulins
}

\author{
Adela Štimac ${ }^{1, *}$, Tihana Kurtović ${ }^{1}$ D, Nediljko Pavlović ${ }^{2}$ and Beata Halassy ${ }^{1, *} \mathbb{D}$ \\ 1 Centre for Research and Knowledge Transfer in Biotechnology, University of Zagreb, Rockefellerova 10, \\ 10000 Zagreb, Croatia; tkurtovi@unizg.hr \\ 2 Institute of Immunology, Inc., Rockefellerova 10, 10000 Zagreb, Croatia; npavlovic@imz.hr \\ * Correspondence: adela.stimac@unizg.hr (A.̌̌.); bhalassy@unizg.hr (B.H.)
}

\section{check for}

updates

Citation: Štimac, A.; Kurtović, T.;

Pavlović, N.; Halassy, B.

Development of Improved

High-Performance Liquid

Chromatography Method for the

Determination of Residual Caprylic

Acid in Formulations of Human

Immunoglobulins. Molecules 2022, 27, 1665. https://doi.org/10.3390/

molecules27051665

Academic Editor: Alexis Oliva

Received: 11 February 2022

Accepted: 1 March 2022

Published: 3 March 2022

Publisher's Note: MDPI stays neutral with regard to jurisdictional claims in published maps and institutional affiliations.

Copyright: (c) 2022 by the authors. Licensee MDPI, Basel, Switzerland. This article is an open access article distributed under the terms and conditions of the Creative Commons Attribution (CC BY) license (https:// creativecommons.org/licenses/by/ $4.0 /)$.

\begin{abstract}
Quality control of human immunoglobulin formulations produced by caprylic acid precipitation necessitates a simple, rapid, and accurate method for determination of residual caprylic acid. A high-performance liquid chromatography method for that purpose was developed and validated. The method involves depletion of immunoglobulins, the major interfering components that produce high background noise, by precipitation with acetonitrile $(1: 1, v / v)$. Chromatographic analysis of caprylic acid, preserved in supernatant with no loss, was performed using a reverse-phase C18 column $(2.1 \times 150 \mathrm{~mm}, 3 \mu \mathrm{m})$ as a stationary phase and water with $0.05 \%$ TFA-acetonitrile $(50: 50, v / v)$ as a mobile phase at a flow rate of $0.2 \mathrm{~mL} / \mathrm{min}$ and run time of $10 \mathrm{~min}$. The developed method was successfully validated according to the ICH guidelines. The validation parameters confirmed that method was linear, accurate, precise, specific, and able to provide excellent separation of peaks corresponding to caprylic acid and the fraction of remaining immunoglobulins. Furthermore, a $2^{4-1}$ fractional factorial design was applied in order to test the robustness of developed method. As such, the method is highly suitable for the quantification of residual caprylic acid in formulations of human immunoglobulins for therapeutic use, as demonstrated on samples produced by fractionation of convalescent anti-SARS-CoV-2 human plasma at a laboratory scale. The obtained results confirmed that the method is convenient for routine quality control.
\end{abstract}

Keywords: caprylic acid; high-performance liquid chromatography method; convalescent anti-SARSCoV-2 human plasma; human immunoglobulins; validation; quality control

\section{Introduction}

Passive immunotherapy involves the administration of antibodies collected from individuals who have recovered from an infection, or have been vaccinated against it, to a patient susceptible to the disease in question. Today, when the whole world is faced with the COVID-19 pandemic induced by the virus named SARS-CoV-2, passive immunotherapy has once again been drawn to attention as the promising treatment option, together with development of refinement strategies for feasible production of effective and safe immunoglobulin G (IgG) preparations [1-4].

Pure IgGs are extracted from pooled plasma collected from convalescent donors by sequence of different fractionation steps, among which the most widely used are precipitation and liquid chromatography [5-10]. Caprylic (octanoic) acid (CA) as a fractionation agent is frequently used to purify IgGs from both animal [11-13] and human plasma [4,14-17], particularly in recent developments of SARS-CoV-2 specific immunoglobulin preparations $[4,18,19]$. CA selectively precipitates non-immunoglobulin proteins without affecting IgGs, which remain in solution, preserving their structural and conformational stability $[6,7,20-22]$. The mechanism of CA-based precipitation is not yet fully understood. 
Morais and Massaldi proposed that CA binds to the specific sites on the proteins, thus increasing the hydrophobicity of their interfacial surfaces and, consequently, protein-protein interactions, which ultimately leads to the precipitation [23].

Residual CA has been considered a process-related impurity; thus, it has to be removed from the final product, and its absence has to be reliably documented. Determination of CA traces has usually been performed by high-performance liquid chromatography (HPLC), gas chromatography, and colorimetric methods [11,24-27]. Herrera et al. [11] described a reverse-phase (RP) HPLC method that was applicable for the antivenom production process. However, the precise and accurate measurement of $\mathrm{CA}$ in a wider concentration range was needed, as we noted during the development of a refinement strategy for fractionation of convalescent anti-SARS-CoV-2 human plasma. Moreover, it was necessary to modify the sample preparation due to the observed loss of CA during the diafiltration process.

Therefore, in this study, we present an improved RP HPLC method for the determination of residual CA in formulations of human IgGs. For its validation, quality control (QC) samples were prepared by spiking of the intravenous immunoglobulin (IVIG) product with a known amount of CA. A procedure for depletion of the interfering IgG fraction from QC samples and elimination of background noise was optimized. The application of developed and validated method was tested on samples obtained before and after the diafiltration step from the CA-mediated protocol for downstream processing of convalescent anti-SARS-CoV-2 human plasma that was established on a laboratory scale.

\section{Results and Discussion}

\subsection{Development of HPLC Method and Sample Preparation}

The aim of this work was to develop a sensitive RP HPLC method that would be suitable for determination of residual CA in samples of IgGs purified from convalescent human plasma, complying the principles of good laboratory practices. HPLC analysis of CA was carried out using an RP C18 column. Different chromatographic conditions were examined, while $0.05 \%$ TFA in water-acetonitrile $(\mathrm{ACN})=50: 50(v / v)$ as the mobile phase and a flow rate of $0.2 \mathrm{~mL} / \mathrm{min}$ were chosen as optimal concerning resolution and separation of CA and IgGs (Table 1). Although IgGs present in samples do not interfere with CA, they produce a background noise in analysis. Even at concentrations as low as $1 \mathrm{mg} / \mathrm{mL}$, the intensity of peaks corresponding to IgGs is much stronger than that produced by residual CA (Figure S1). Considering that expected concentrations of IgGs in fractions from human plasma processing would be at least fivefold higher, elimination of the background noise in QC samples was a necessary prerequisite prior validation and, later on, implementation of the developed method for the quality control. According to the literature, interfering IgGs could be removed by ultrafiltration in a centrifugal filter unit of $10 \mathrm{kDa}$ nominal molecular weight limit [11] or by their precipitation with ACN [14] or ACN/trifluoracetic acid (TFA) [24].

Table 1. Optimized chromatographic conditions.

\begin{tabular}{ll}
\hline Parameter & Chromatographic Condition \\
\hline Mobile phase & $0.05 \%$ TFA in water-ACN $(50: 50, v / v)$ \\
Flow rate & $0.2 \mathrm{~mL} / \mathrm{min}$ \\
Mode & Isocratic \\
Run time & $10 \mathrm{~min}$ \\
Injection volume & $5 \mu \mathrm{L}$ \\
Detection wavelength & $210 \mathrm{~nm}$ \\
Temperature & Ambient temperature \\
\hline
\end{tabular}

Therefore, for efficient elimination of IgGs from QC samples, diafiltration and precipitation of IVIG with various solvents were examined. First, diafiltration in a centrifugal filter unit of $100 \mathrm{kDa}$ nominal molecular weight limit (Vivaspin ${ }^{\circledR} 20 \mathrm{~mL} 100 \mathrm{kDa}$ PES) was attempted, but recovery of CA in filtrate was only about $75 \%$. In order to determine 
possible causes of partial loss of CA during diafiltration process, its amount in retentate and filtrate of QC samples $(10 \mathrm{~mL})$, as well as in samples obtained by rinsing the centrifugal filter unit three times with water $(10 \mathrm{~mL})$, was measured. The results revealed that the filtrates had about $75 \% \mathrm{CA}$, and the retentates had $2-4 \%$ CA (Figure 1 ). The remaining CA very likely bound to the membrane of centrifugal filter unit, given that it could be released and washed by rinsing with water. The concentration of CA in filtrates obtained by rinsing (filtrates 1, 2 and 3) decreased after each cycle of diafiltration. Moreover, the rinsing efficiency was higher in sample with the lowest CA concentration (300 ppm), which can be explained by the higher solubility of CA in water (the solubility of CA in water is $0.068 \mathrm{~g}$ in $100 \mathrm{~mL}, 750 \mathrm{ppm}$ ). In order to achieve complete recovery, it would be necessary to perform additional rinsing cycles, but then the CA concentration in the filtrates would be below the LOQ value of the method.

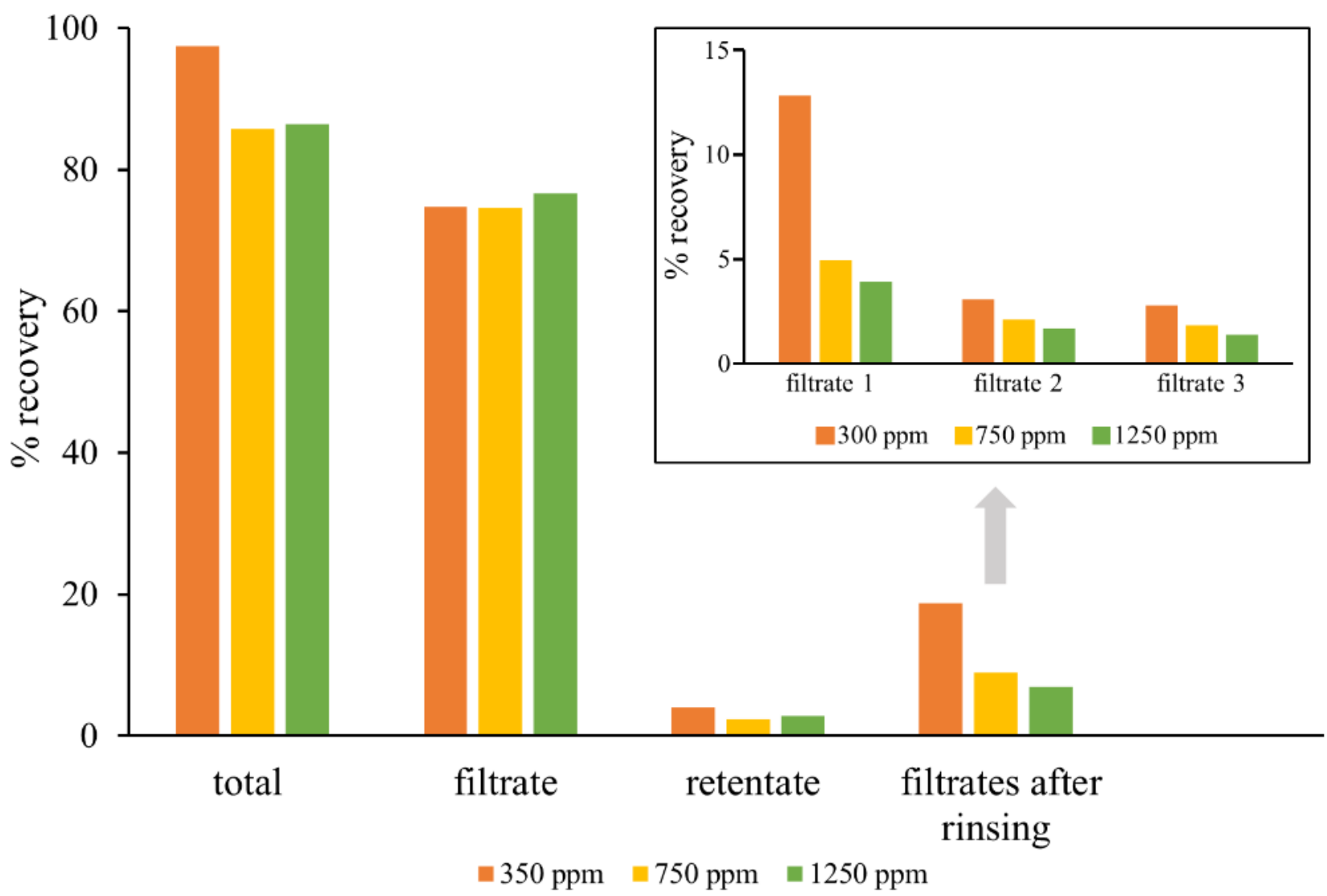

Figure 1. Monitoring of CA recovery in QC samples during diafiltration process by determination of its amount in filtrate, retentate, and filtrates that were obtained after three rinsing cycles with water.

Therefore, precipitation of IgGs with ACN (with or without TFA), methanol, and ethanol was investigated. Addition of one volume of acetonitrile almost completely precipitated IgGs, in contrast to methanol and ethanol, which appeared completely ineffective. The addition of TFA in ACN did not bring any improvement to precipitation; thus, ACN was selected as the optimal precipitating agent. Furthermore, although an increase in ACN content from one to two volumes had a beneficial impact on IgG precipitation in QC samples, it resulted in over-dilution of CA traces, thus decreasing the sensitivity of the assay. Therefore, before HPLC analysis, IgGs in QC samples were precipitated by ACN $(1: 1, v / v)$ and removed by centrifugation. The obtained supernatants gave a convenient separation profile, as well as a high recovery and reproducibility of CA in QC samples. 


\subsection{Validation}

The developed HPLC method was validated in terms of specificity, linearity, precision, accuracy, limit of detection (LOD), limit of quantification (LOQ), and robustness, according to International Conference on Harmonization (ICH) guidelines [28].

\subsubsection{Specificity}

The method specificity refers to the ability to accurately measure the analyte response in the presence of all potential matrix components. The amount of IgGs, retained in QC samples after precipitation with ACN, was sufficiently low and did not interfere with CA quantification by the HPLC method, as demonstrated by complete separation of the CA $(\mathrm{RT}=8.4 \mathrm{~min})$ from the $\mathrm{IgG}(\mathrm{RT}=2.1 \mathrm{~min})$ peak (Figure 2$)$. Therefore, the method was confirmed as specific and suitable for CA quantification in QC samples.

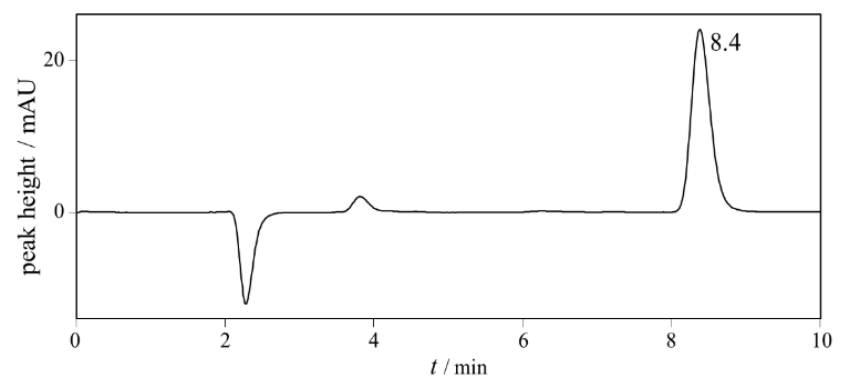

(a)

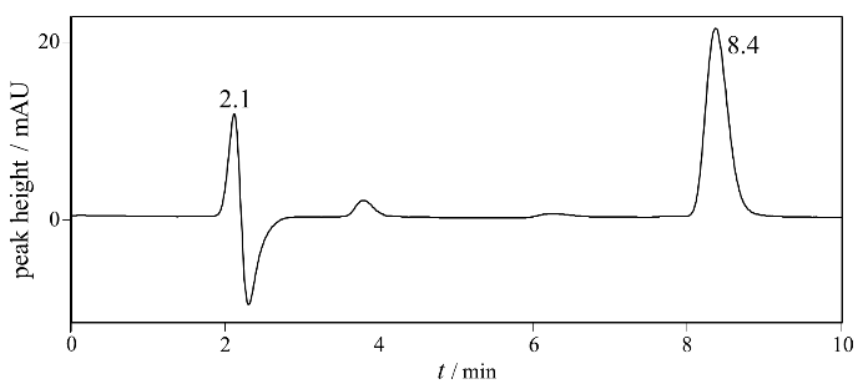

(b)

Figure 2. HPLC chromatograms of (a) caprylic acid and (b) QC samples (IVIG sample spiked with CA) after precipitation of IgGs by ACN. Chromatographic conditions are given in Table 1.

\subsubsection{Linearity}

The linearity of the method was evaluated by analyzing seven different concentrations of CA standard solutions, each run in duplicate. The calibration curves were obtained by plotting the peak area versus the amount of CA by the least-square linear regression analysis. The method was found to be linear in the range of 25-2500 ppm CA $(22.75-2275 \mu \mathrm{g} / \mathrm{mL})$ and appropriate for measuring the amount of $\mathrm{CA}$ in samples from fractionation of convalescent anti-SARS-CoV-2 human plasma (Figure S2). This range of CA concentrations is much wider than the range reported by Herrera et al. $(400-600 \mu \mathrm{g} / \mathrm{mL})$ [11]. The $R^{2}$ values for the calibration curves obtained from analyses independently performed over three consecutive days were found to be greater than 0.999 , indicating a linear relationship between the amount of CA and peak area. ANOVA analysis (Table 2) proved that there was linear regression with no deviation from linearity $(p<0.05)$.

Table 2. Results of analysis of variance (ANOVA) for linearity.

\begin{tabular}{lccccc}
\hline & df & Sum of Squares & Mean Square & F & Significance F * \\
\hline Regression & 1 & $6.62 \times 10^{12}$ & $6.62 \times 10^{12}$ & $68,106.87$ & $2.96 \times 10^{-66}$ \\
Residual & 40 & $3.89 \times 10^{9}$ & $97,259,462$ & & \\
Total & 41 & $6.63 \times 10^{12}$ & & & \\
\hline
\end{tabular}

* Significance $\mathrm{F}$ is the $p$-value of $\mathrm{F}$.

\subsubsection{Precision and Accuracy}

Precision is the closeness of a series of measurements obtained from multiple sampling of the same sample, and it was determined by measuring repeatability (intra-day) and intermediate precision (inter-day) over three consecutive days. The intra-day and inter-day precision of the proposed method was measured by analyzing three concentration levels of QC samples, each in hexaplicate, on three separate days. Method precision was expressed 
in terms of percentage RSD. The values of the percentage RSD obtained for intra-day and inter-day precision measurement were in the range of $0.457-0.848 \%$ and $0.746-1.069 \%$, respectively (Table 3). All obtained percentage RSD values $(<2 \%)$ confirmed the precision of the method.

The accuracy of the method is the closeness of the measurement between the true and the found value, and it is usually determined by spiking known amounts of standard into the sample. The accuracy of the developed method was determined by calculating the percentage recovery of CA in QC samples spiked with CA at three concentration levels, each in hexaplicate. The amount of CA was calculated by applying obtained values to regression equations. The percentage recovery of CA (intra- and inter-day) was found to be in the range of $98.58-101.02 \%$ (Table 3), which confirms the accuracy of developed method.

Table 3. Precision (intra- and inter-day) and accuracy of the method for determination of CA concentration in IVIG samples.

\begin{tabular}{|c|c|c|c|c|}
\hline & $\begin{array}{l}\text { Nominal Amount of } \\
\text { CA in ppm }\end{array}$ & $\begin{array}{c}\text { Measured Amount of } \\
\text { CA in ppm (Mean } \pm \text { SD) }\end{array}$ & $\%$ RSD & $\begin{array}{c}\% \text { Recovery } \\
(\text { Mean } \pm \text { SD) }\end{array}$ \\
\hline \multicolumn{5}{|l|}{ Intra-day precision ${ }^{a}$} \\
\hline \multirow{3}{*}{ 1st day } & 300 & $303.06 \pm 1.74$ & 0.575 & $101.02 \pm 0.58$ \\
\hline & 750 & $753.68 \pm 5.30$ & 0.703 & $100.49 \pm 0.71$ \\
\hline & 1250 & $1249.33 \pm 10.36$ & 0.829 & $99.94 \pm 0.83$ \\
\hline \multirow{3}{*}{ 2nd day } & 300 & $297.08 \pm 1.09$ & 0.669 & $99.03 \pm 0.36$ \\
\hline & 750 & $739.37 \pm 3.93$ & 0.671 & $98.58 \pm 0.52$ \\
\hline & 1250 & $1243.27 \pm 7.98$ & 0.642 & $99.46 \pm 0.64$ \\
\hline \multirow{3}{*}{ 3rd day } & 300 & $302.31 \pm 2.56$ & 0.848 & $100.77 \pm 0.85$ \\
\hline & 750 & $740.83 \pm 3.38$ & 0.457 & $98.78 \pm 0.49$ \\
\hline & 1250 & $1252.12 \pm 8.67$ & 0.692 & $100.17 \pm 0.69$ \\
\hline \multirow{3}{*}{ Inter-day precision $b$} & 300 & $301.04 \pm 3.22$ & 1.069 & $100.35 \pm 1.07$ \\
\hline & 750 & $744.39 \pm 7.64$ & 1.027 & $99.25 \pm 1.02$ \\
\hline & 1250 & $1248.24 \pm 9.32$ & 0.746 & $99.86 \pm 0.75$ \\
\hline
\end{tabular}

${ }^{a} n=6$ for each amount of CA. ${ }^{b} n=18$ for each amount of CA ( 3 days $\times 6$ samples).

Herrera et al. [11] reported that recovery of CA was between $98.8 \%$ and $100.7 \%$, and that intra-day precision was $<2.1 \%$. Concerning recovery, we obtained comparable values. In our study, even lower intra-day precision was achieved $(<0.85 \%)$. Since they did not evaluate inter-day precision, a comparison is not feasible.

\subsubsection{Limit of Detection (LOD) and Limit of Quantification (LOQ)}

The LOD of an analytical method is the lowest analytical concentration at which an analyte can be detected qualitatively, while LOQ is the lowest concentration of the analyte that can be quantitated with acceptable precision. According to ICH guidelines [28], the LOD and LOQ may be determined by visual evaluation, signal-to-noise ratio (S/N), or calculation based on the standard deviation (SD) of the response and slope of the calibration curve. It was shown previously that LOD and LOQ can differ depending on the used method (visual evaluation, $\mathrm{S} / \mathrm{N}$ ratio, or the calibration line method). Even within the calibration line method, quite different results can be obtained, depending on whether the SD of the regression line or the SD of the $y$-intercept is used [29-32].

In the present study, the LOD and LOQ values of the developed method were determined on the basis of both the $\mathrm{S} / \mathrm{N}$ ratio and the calibration curve using samples containing CA at low concentrations (Table 4). The LOD and LOQ values were calculated with two different calibration curve methods according to LOD $=3.3 \sigma / S$ and LOQ $=10 \sigma / S$. In the first method, $\sigma$ is the residual SD of a regression line; in the second method, $\sigma$ is the SD of the $y$-intercept. 
Table 4. LOD and LOQ values determined by S/N ratio and SD of the response (SD of a regression line or SD of the $y$-intercept) and slope of the calibration curves.

\begin{tabular}{cccc}
\hline & S/N & SD of Regression Line & SD of $\boldsymbol{y}$-Intercept \\
\hline LOD & $8 \mathrm{ppm}$ & $10.3 \pm 1.1 \mathrm{ppm}$ & $7.0 \pm 0.7 \mathrm{ppm}$ \\
LOQ & $25 \mathrm{ppm}$ & $31.3 \pm 3.4 \mathrm{ppm}$ & $21.1 \pm 2.2 \mathrm{ppm}$ \\
\hline
\end{tabular}

* Mean \pm SD of calibration curves on three separate days.

LOD and LOQ values determined by all three methods were similar and proved the sensitivity of the developed HPLC method. Furthermore, obtained values were lower than those obtained by Herrera et al. [11]. They determined a value of $13.46 \mu \mathrm{g} / \mathrm{mL}$ for LOD and a value of $44.85 \mu \mathrm{g} / \mathrm{mL}$ for LOQ, while our obtained values were $8 \mathrm{ppm}(7.28 \mu \mathrm{g} / \mathrm{mL})$ for LOD and $25 \mathrm{ppm}(22.75 \mu \mathrm{g} / \mathrm{mL})$ for LOQ. Alonso et al. [17] and Valdenberg et al. [18] reported that their IgG products contained less than $8 \mu \mathrm{g} / \mathrm{mL} \mathrm{CA}$, albeit without specifying the method; hence, a comparison is not possible. The method presented here would obviously be suitable for the control of CA impurities, being equally sensitive.

\subsubsection{Robustness}

The robustness examines the reliability of an analysis with respect to slight variations in method conditions and parameters [28,33]. Selected variations in this method included $\mathrm{pH} \pm 0.2$ units, wavelength $\pm 2 \mathrm{~nm}$, ACN solvent ratio $(v / v)$ in the mobile phase $(\% \mathrm{ACN}) \pm 5 \%$, and flow rate $\pm 0.02 \mathrm{~mL} / \mathrm{min}$. The effect of selected operating factors $(\mathrm{pH}$, wavelength, \%ACN, and flow rate), each at two levels, was assessed using four-factor fractional factorial design $\left(2^{4-1}\right)$, requiring the performance of eight experimental runs. The evaluation of responses measured in a robustness test for chromatographic methods includes quantitative aspects responses (e.g., area) and system suitability test (SST) responses (e.g., resolution) [28,33]. The retention time (RT), peak area (A), theoretical plate number $(\mathrm{N})$, resolution $(\mathrm{R})$, capacity factor $\left(\mathrm{k}^{\prime}\right)$, and tailing factor were chosen as response variables and were determined in all experimental runs (Table 5). According to Food and Drug Administration recommendations [34], a system is suitable when values for N, R, $k^{\prime}$, and tailing factor are $>2000,>2,>2$, and $\leq 2$, respectively. All obtained values of SST responses were within the recommended values, which indicated good column efficiency, good resolution, good retention on the column, and symmetry of the peak.

Table 5. Values (average \pm standard deviation) of obtained responses for eight experiments of fractional factorial design (FFD).

\begin{tabular}{ccccccc}
\hline Experiment & RT & $\mathbf{A}$ & $\mathbf{N}$ & $\mathbf{R}$ & $\mathbf{k}^{\prime}$ & Tailing Factor \\
\hline 1 & $12.30 \pm 0.01$ & $377.79 \pm 5.43$ & $5064 \pm 54$ & $18.38 \pm 0.13$ & $4.15 \pm 0.01$ & $1.197 \pm 0.012$ \\
2 & $10.18 \pm 0.05$ & $312.55 \pm 4.55$ & $4632 \pm 32$ & $18.13 \pm 0.02$ & $4.21 \pm 0.02$ & $1.179 \pm 0.005$ \\
3 & $10.17 \pm 0.01$ & $302.32 \pm 4.26$ & $4712 \pm 30$ & $17.88 \pm 0.13$ & $4.10 \pm 0.01$ & $1.176 \pm 0.006$ \\
4 & $12.35 \pm 0.03$ & $369.27 \pm 4.39$ & $5115 \pm 33$ & $19.09 \pm 0.04$ & $4.27 \pm 0.02$ & $1.183 \pm 0.005$ \\
5 & $6.03 \pm 0.02$ & $293.72 \pm 2.93$ & $2744 \pm 24$ & $10.64 \pm 0.15$ & $2.15 \pm 0.01$ & $1.222 \pm 0.004$ \\
6 & $7.24 \pm 0.01$ & $358.67 \pm 2.87$ & $3029 \pm 9$ & $11.56 \pm 0.07$ & $2.17 \pm 0.01$ & $1.224 \pm 0.002$ \\
7 & $7.23 \pm 0.01$ & $354.06 \pm 2.57$ & $3051 \pm 4$ & $11.06 \pm 0.14$ & $2.13 \pm 0.01$ & $1.234 \pm 0.002$ \\
8 & $6.02 \pm 0.01$ & $292.91 \pm 2.37$ & $2732 \pm 12$ & $10.98 \pm 0.04$ & $2.16 \pm 0.01$ & $1.225 \pm 0.004$ \\
\hline
\end{tabular}

The evaluated simple effects (E) of four selected operating factors on each of six observed responses indicated that percentage ACN induced the highest, mostly negative shift in monitored responses (Table 6). 
Table 6. Obtained simple effect (E) of a given factor on each of the monitored responses.

\begin{tabular}{|c|c|c|c|c|c|c|}
\hline Factor & E on RT & E on $A$ & E on $N$ & E on $R$ & E on $\mathbf{k}^{\prime}$ & E on Tailing Factor \\
\hline $\mathrm{pH}$ & 0.01317 & 1.3764 & -15.92 & 0.44417 * & 0.06942 & -0.0043 \\
\hline $\begin{array}{l}\text { Wavelength } \\
\text { (nm) }\end{array}$ & 0.00383 & -6.0396 & 35.58 & 0.07483 & 0.00092 & -0.0010 \\
\hline$\% A C N(v / v)$ & $-4.61700 *$ & $-15.6454 *$ & $-1991.75 *$ & $-7.30983 *$ & $-2.03008^{*}$ & 0.0425 * \\
\hline $\begin{array}{l}\text { Flow rate } \\
(\mathrm{mL} / \mathrm{min})\end{array}$ & $-1.68467 *$ & -64.5738 * & $-359.58 *$ & -0.61583 * & -0.02658 & -0.0088 \\
\hline
\end{tabular}

In order to identify statistically significant effects, standardized effects were estimated as the ratio of simple effect and standard error of an effect. The standardized effects of examined operating factors on monitored responses are presented in a Pareto chart (Figure 3), which demonstrates the absolute values of the standardized effects and plots a reference line to indicate which effects are statistically significant $(p=0.05)$. It was observed that both the percentage can content in the mobile phase and the flow rate had significant negative effects on retention time, peak area, theoretical plate number, and resolution, which means that an increase in the effect factor level decreased the response value. Moreover, the percentage ACN content by itself had a significant negative effect on the capacity factor and positive effect on the tailing factor. Hence, it was identified as the most crucial factor, impairing all responses, followed by flow rate. The $\mathrm{pH}$ had only a small positive effect on peak resolution. The wavelength had no effect on any response. Therefore, the percentage ACN content in the mobile phase and flow rate should be strictly regulated during method performance.

\subsection{Application of Developed Method}

The suitability of the developed method for the routine quality control was examined by employing IgG fractions from downstream processing of convalescent anti-SARS-CoV human plasma. The refinement strategy was developed at a laboratory scale to provide a safe and effective treatment option for COVID-19. Briefly, IgGs were obtained by precipitation with 5\% CA (crude IgG) and were subsequently diafiltrated for CA removal (pure $\mathrm{IgG}$ ) using a centrifugal filter unit of $100 \mathrm{kDa}$ nominal molecular weight limit. In order to achieve the highest possible degree of CA removal, the diafiltration process was repeated three times. The initial sample (before diafiltration) was diluted threefold with buffer, while obtained retentates in every diafiltration cycle were diluted around 50-fold (manuscript in preparation). The developed method was used to investigate the amount of CA in the initial sample (crude IgG, before diafiltration), in the filtrates after each diafiltration cycle, and in the final product (pure IgG, after diafiltration). Crude and pure IgG were prepared for HPLC analysis by precipitation with ACN in order to remove IgGs, while filtrates were submitted to HPLC analysis without any additional treatment. After the first diafiltration cycle, the majority of CA was removed (Figure 4), ending in filtrate 1 (resulting quantity was below the known CA solubility in water). In filtrate 3, as well as in the final product, the amount of CA was in the range of the LOQ value of the method. The sum of CA amounts in all filtrates and in pure IgG corresponded to the amount of CA in the initial sample, confirming the accuracy of the method and its suitability for the routine analysis of residual CA in human IgG preparations. Additionally, in the case of crude IgG diafiltration, successful removal of CA from the solution and its desorption from the membrane of the centrifugal filter unit by extensive washing were demonstrated. 


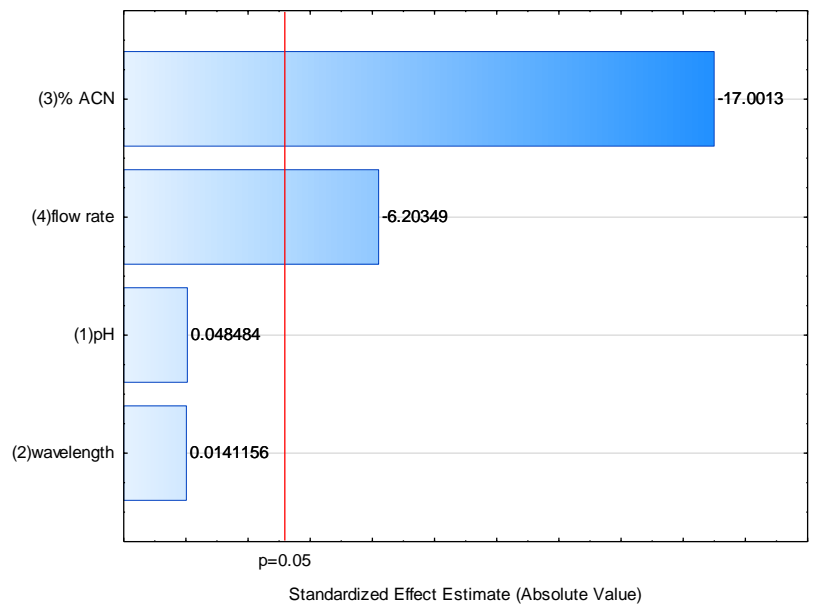

(a)

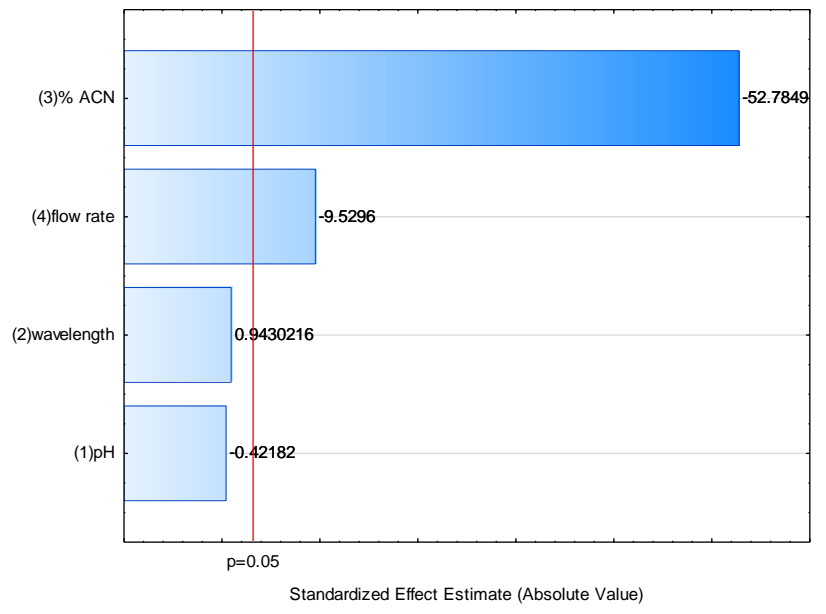

(c)

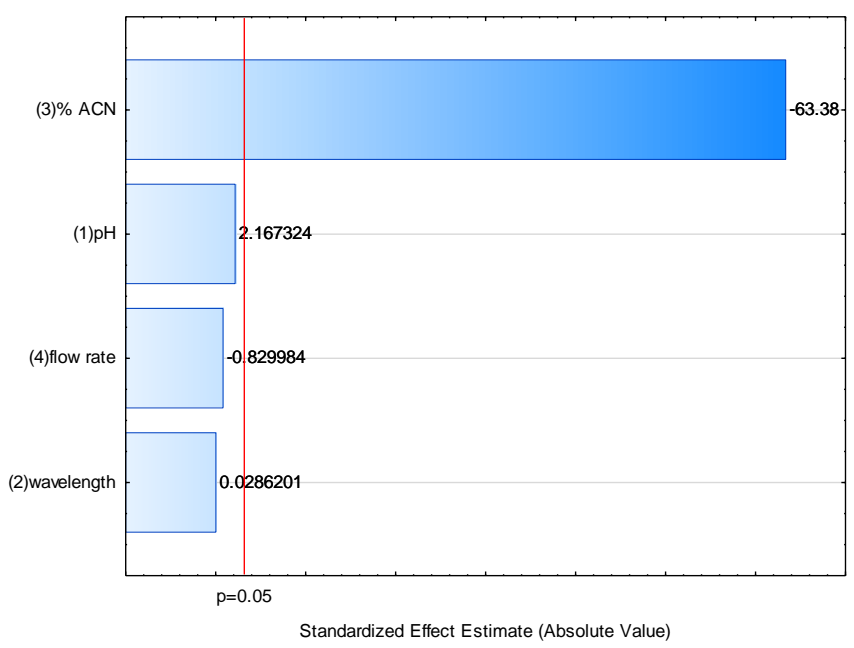

(e)

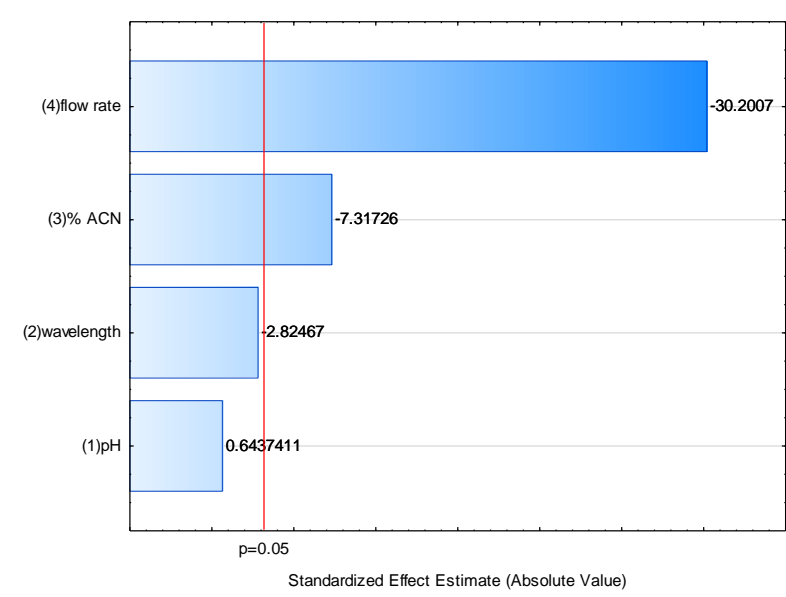

(b)

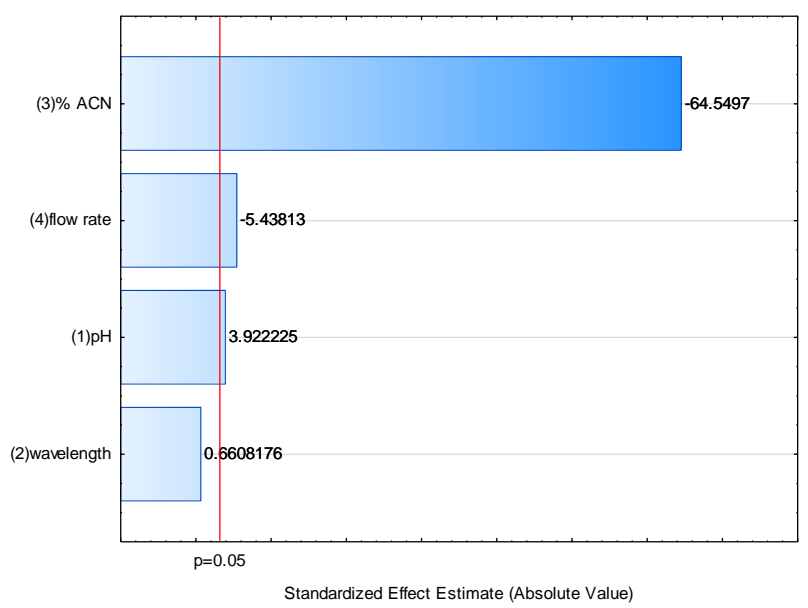

(d)

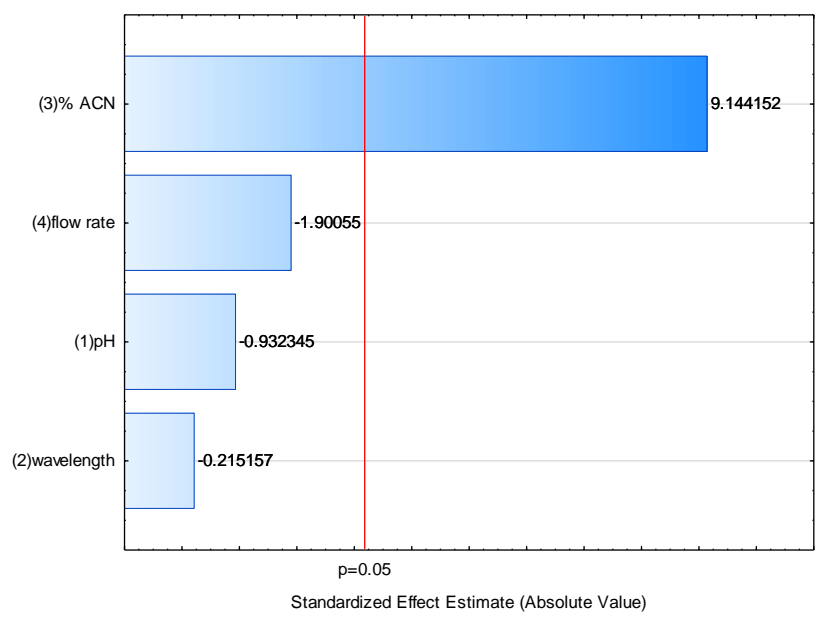

(f)

Figure 3. Pareto charts of standardized effects of examined operating factors (\%ACN, flow rate, $\mathrm{pH}$, wavelength) on responses: (a) retention time; (b) peak area; (c) theoretical plate number; (d) resolution; (e) capacity factor; (f) tailing factor. 


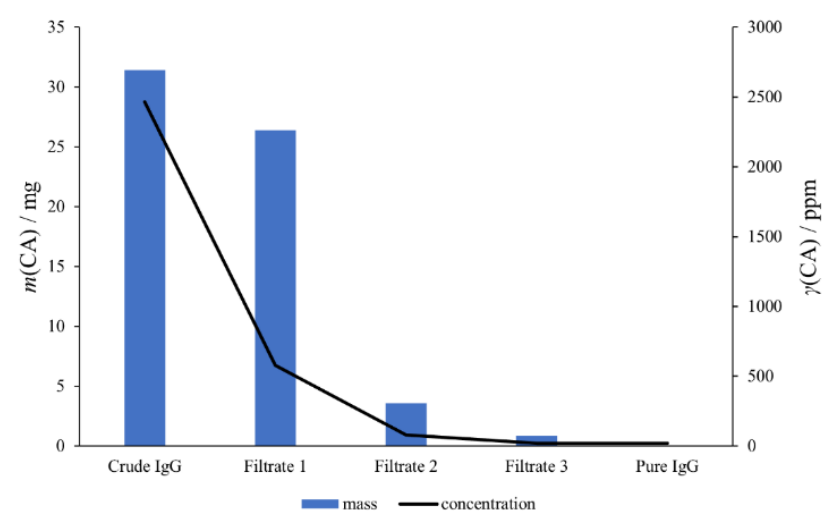

Figure 4. CA removal monitoring during diafiltration step of the refinement protocol for IgG purification, performed by quantification of CA amount in crude IgG, filtrates after each diafiltration step, and final pure IgG.

\section{Materials and Methods}

\subsection{Reagents and Chemicals}

HPLC-grade acetonitrile (ACN) was purchased from Merck (Darmstadt, Germany), while HPLC-grade trifluoroacetic acid (TFA) and caprylic acid (CA) were from SigmaAldrich (St. Louis, MO, USA). A daily supply of ultrapure water was obtained from a PureLab Classic purification system (Elga, UK). Human Immunoglobulin for intravenous application (IVIG, $50 \mathrm{mg} / \mathrm{mL}$ ) was from Institute of Immunology Inc. (Zagreb, Croatia).

\subsection{Standard Solutions and Quality Control Sample Preparation}

Concentrated stock solution (5\% CA) was prepared by adding $50 \mu \mathrm{L}$ of CA to $950 \mu \mathrm{L}$ of ACN and filtering through a hydrophobic PTFE $0.2 \mu \mathrm{m}$ filter (Dissolution Accessories, Oosterhout, Netherlands). The working standard solution ( $0.5 \% \mathrm{CA})$ was prepared by diluting stock solution 10-fold with mobile phase and used for further preparation of seven standard samples that covered the concentration range of 25-2500 ppm (0.0025-0.25\%).

Quality control (QC) samples were prepared by spiking an IVIG solution $(5 \mathrm{mg} / \mathrm{mL})$ with an appropriate volume of $0.5 \%$ CA. In order to eliminate background noise, IVIG from QC samples was depleted prior to HPLC analysis by precipitation with one volume of ACN. Precipitates were removed by centrifugation (Eppendorf, Germany) at $3000 \times g$ for $45 \mathrm{~min}$, and supernatants were transferred to $1.5 \mathrm{~mL}$ vials for HPLC analysis. Final amounts of CA in QC samples were 300, 750, and 1250 ppm. The quantification of CA was based on a CA calibration curve.

Stock solutions and samples were freshly prepared prior analysis. Each standard solution was prepared in duplicate and each QC sample was prepared in hexaplicate.

\subsection{HPLC Instrumentation and Conditions}

HPLC analysis was carried out using a Shimadzu Prominence LC-20AD with UV detector SPD-M20A, autosampler SIL20AC HT, and LabSolutions software (Kyoto, Japan). The chromatographic separation was performed on a Shim pack GIST C18 column, $2.1 \times 150 \mathrm{~mm}, 3 \mu \mathrm{m}$ (Shimadzu, Japan), fitted with a guard cartridge packed with the same stationary phase. The mobile phase consisted of a mixture of $0.05 \%$ TFA in water (A) and ACN (B) $(50: 50, v / v)$. An RP HPLC analysis was performed in isocratic mode at a flow rate of $0.2 \mathrm{~mL} / \mathrm{min}$ at room temperature. A wavelength of $210 \mathrm{~nm}$ was used for detection. The injection volume was $5 \mu \mathrm{L}$, and the total run time was $10 \mathrm{~min}$.

\subsection{Validation Parameters of Developed Method}

The developed HPLC method was validated according to the ICH guidelines [28]. The parameters studied for the validation included specificity, linearity, precision (repeatability 
and intermediate precision), accuracy, limit of detection (LOD), limit of quantitation (LOQ), and robustness.

\subsubsection{Specificity}

The specificity of the method was assessed from chromatographic runs of standard solutions and QC samples. The retention time (RT) of CA in standard solutions and QC samples, and the separation of CA and IVIG peaks in QC samples were selected as comparison parameters.

\subsubsection{Linearity}

In order to determine the linearity of the method, three independent calibration curves were constructed using seven standard solutions of CA prepared in duplicates, covering the range of 25-2500 ppm. Calibration curves were obtained by plotting the peak area of each standard solution as a function of amount of CA. Linearity was evaluated by linear regression analysis, using the least square linear regression method and ANOVA test in Excel $(\alpha=0.05)$.

\subsubsection{Precision and Accuracy}

Precision was determined by repeatability (intra-day precision) and intermediate precision (inter-day precision). QC samples at three different levels of CA (300, 750, and $1250 \mathrm{ppm}$ ) were prepared in hexaplicates $(n=6)$ and analyzed according to the proposed method (for intra-day precision and accuracy) over three consecutive days (for inter-day precision and accuracy). The precision was expressed as percentage relative standard deviation (\% RSD) of the assay results, and the accuracy was expressed as the percentage recovery for each concentration of CA in QC samples according to Equation (1).

$$
\text { accuracy }(\% \text { recovery })=(\text { measured concentration } / \text { nominal concentration }) \times 100 \text {. }
$$

\subsubsection{Limit of Detection (LOD) and Limit of Quantification (LOQ)}

The limit of detection (LOD) and the limit of quantitation (LOQ) values were determined on the basis of either the signal-to-noise ratio $(\mathrm{S} / \mathrm{N})$ or a calibration curve. In both cases, analysis of standard solutions with low CA concentrations was performed. In the first approach, LOD and LOQ were determined at $\mathrm{S} / \mathrm{N}$ ratios of 3:1 and 10:1, respectively.

In the second approach, LOD and LOQ were determined on the basis of calibration curves and calculated according to Equations (2) and (3).

$$
\begin{aligned}
& \mathrm{LOD}=3.3 \frac{\sigma}{S} \\
& \mathrm{LOQ}=10 \frac{\sigma}{S}
\end{aligned}
$$

where $\sigma$ is the residual standard deviation of a regression line or the standard deviation of the $y$-intercept, and $S$ is the slope of the calibration curve.

\subsubsection{Robustness}

The robustness was investigated by testing the influence of small changes in $\mathrm{pH}$ value, wavelength, percentage ACN content in the mobile phase, and flow rate on the chromatographic behavior of CA. The interval between low and high level for each factor was placed symmetrically around the nominal level (Table 7). In order to study the robustness, four-factor fractional factorial design (FFD) was employed $\left(2^{4-1}\right)$. The experimental design resulted in eight chromatographic runs that were performed independently (Table 8). Each run consisted of three replicate injections of QC sample. The response variables were the retention time $(\mathrm{RT})$, peak area $(\mathrm{A})$, theoretical plate number $(\mathrm{N})$, resolution $(\mathrm{R})$, capacity factor $\left(\mathrm{k}^{\prime}\right)$, and tailing factor. TIBCO Statistica ${ }^{\circledR}$ Version 14.0 (Palo Alto, CA, USA) and 
Microsoft Office Excel 2019 (Redmont, WA, USA) were used for the statistical evaluation of the obtained data.

Table 7. Experimental factors and levels.

\begin{tabular}{lccc}
\hline \multicolumn{1}{c}{ Factors } & Low Level & Nominal Level & High Level \\
\hline $\mathrm{pH}$ & 2.2 & 2.4 & 2.6 \\
Wavelength $(\mathrm{nm})$ & 208 & 210 & 212 \\
\%ACN $(v / v)$ & 45 & 50 & 55 \\
Flow rate $(\mathrm{mL} / \mathrm{min})$ & 0.18 & 0.2 & 0.22 \\
\hline
\end{tabular}

Table 8. The total of eight experiments proposed by the software for FFD.

\begin{tabular}{ccccc}
\hline Experiment Number & $\mathbf{p H}$ & Wavelength $(\mathbf{n m})$ & \%ACN $(\boldsymbol{v} / \mathbf{v})$ & Flow Rate $(\mathbf{m L} / \mathbf{m i n})$ \\
\hline 1 & 2.2 & 208 & 45 & 0.18 \\
2 & 2.6 & 208 & 45 & 0.22 \\
3 & 2.2 & 212 & 45 & 0.22 \\
4 & 2.6 & 212 & 55 & 0.18 \\
5 & 2.2 & 208 & 55 & 0.22 \\
6 & 2.6 & 208 & 55 & 0.18 \\
7 & 2.2 & 212 & 55 & 0.18 \\
8 & 2.6 & 212 & 0.22 \\
\hline
\end{tabular}

\section{Conclusions}

A simple, sensitive, and rapid RP HPLC method for the determination of CA in IVIG according to the principles of good laboratory practices was successfully developed and validated under optimized conditions. The validation parameters confirmed linearity, accuracy, precision, and specificity of developed method, which provided excellent separation of CA from IgG and enabled quantification of CA in IVIG. The robustness of the developed method was evaluated using fractional factorial design. Special attention should be paid to the percentage $\mathrm{ACN}$ in the mobile phase and flow rate as experimental factors that have a significant impact on the chromatographic behavior of CA and, as such, should be strictly regulated during the performance of the method. The application check of the method demonstrated its appropriateness for the routine analysis of residual CA in intermediates and final products of human IgGs for passive immunotherapy in quality control.

Supplementary Materials: The following supporting information can be downloaded online. Figure S1. Representative HPLC chromatogram of IVIG sample $(1 \mathrm{mg} / \mathrm{mL})$ spiked with caprylic acid $(0.5 \%, v / v)$. Chromatographic conditions are given in Table 1; Figure S2. Example of calibration curve of CA.

Author Contributions: Conceptualization, A.Š., T.K. and B.H.; methodology, A.Š. and T.K.; validation, A.Š.; formal analysis, A.Š. and N.P.; investigation, A.Š.; resources, B.H.; data curation, A.Š. and N.P.; writing—original draft preparation, A.Š.; writing—review and editing, T.K., N.P. and B.H.; visualization, T.K. and B.H.; supervision, B.H.; project administration, B.H.; funding acquisition, B.H. All authors read and agreed to the published version of the manuscript.

Funding: The work was funded by the Croatian Science Foundation, grant number IP-CORONA04-2053 to B.H. and by the European Regional Development Fund, grant number KK.01.1.1.01.0006, "Strengthening the capacity of CerVirVac for research in virus immunology and vaccinology".

Data Availability Statement: The data presented in this study are available on request from the corresponding author.

Conflicts of Interest: The authors declare no conflict of interest.

Sample Availability: Not available. 


\section{References}

1. Casadevall, A.; Dadachova, E.; Pirofski, L.A. Passive Antibody Therapy for Infectious Diseases. Nat. Rev. Microbiol. 2004, 2, 695-703. [CrossRef]

2. Abraham, J. Passive Antibody Therapy in COVID-19. Nat. Rev. Immunol. 2020, 20, 401-403. [CrossRef] [PubMed]

3. Casadevall, A.; Pirofski, L.A. The Convalescent Sera Option for Containing COVID-19. J. Clin. Investig. 2020, 130, 1545-1548. [CrossRef] [PubMed]

4. $\quad$ Ali, S.; Uddin, S.M.; Ali, A.; Anjum, F.; Ali, R.; Shalim, E.; Khan, M.; Ahmed, I.; Muhaymin, S.M.; Bukhari, U.; et al. Production of Hyperimmune Anti-SARS-CoV-2 Intravenous Immunoglobulin from Pooled COVID-19 Convalescent Plasma. Immunotherapy 2021, 13, 397-407. [CrossRef] [PubMed]

5. Buchacher, A.; Iberer, G. Purification of Intravenous Immunoglobulin G from Human Plasma-Aspects of Yield and Virus Safety. Biotechnol. J. 2006, 1, 148-163. [CrossRef]

6. Russo, C.; Callegaro, L.; Lanza, E.; Ferrone, S. Purification of IgG Monoclonal Antibody by Caprylic Acid Precipitation. J. Immunol. Methods 1983, 65, 269-271. [CrossRef]

7. Temponi, M.; Kageshita, T.; Perosa, F.; Ono, K.; Okada, H.; Ferrone, S. Purification of Murine IgG Monoclonal Antibodies by Precipitation with Caprylic Acid: Comparison with Other Methods of Purification. Hybridoma 1989, 8, 85-95. [CrossRef]

8. Eliasson, M.; Olsson, A.; Palmcrantz, E.; Wiberg, K.; Inganas, M.; Guss, B.; Lindberg, M.; Uhlen, M. Chimeric IgG-Binding Receptors Engineered from Staphylococcal Protein A and Streptococcal Protein G. J. Biol. Chem. 1988, 263, 4323-4327. [CrossRef]

9. Roque, A.C.A.; Silva, C.S.O.; Taipa, M.Â. Affinity-Based Methodologies and Ligands for Antibody Purification: Advances and Perspectives. J. Chromatogr. A 2007, 1160, 44-55. [CrossRef]

10. Bergmann-Leitner, E.S.; Mease, R.M.; Duncan, E.H.; Khan, F.; Waitumbi, J.; Angov, E. Evaluation of Immunoglobulin Purification Methods and Their Impact on Quality and Yield of Antigen-Specific Antibodies. Malar. J. 2008, 7, 1-10. [CrossRef]

11. Herrera, M.; Meneses, F.; Gutiérrez, J.M.; León, G. Development and Validation of a Reverse Phase HPLC Method for the Determination of Caprylic Acid in Formulations of Therapeutic Immunoglobulins and Its Application to Antivenom Production. Biologicals 2009, 37, 230-234. [CrossRef] [PubMed]

12. Kurtović, T.; Balija, M.L.; Brgles, M.; Sviben, D.; Tunjić, M.; Cajner, H.; Marchetti-Deschmann, M.; Allmaier, G.; Halassy, B. Refinement Strategy for Antivenom Preparation of High Yield and Quality. PLoS Negl. Trop. Dis. 2019, 13, e0007431. [CrossRef] [PubMed]

13. Kurtović, T.; Brgles, M.; Balija, M.L.; Steinberger, S.; Sviben, D.; Marchetti-Deschmann, M.; Halassy, B. Streamlined Downstream Process for Efficient and Sustainable (Fab')2 Antivenom Preparation. J. Venom. Anim. Toxins Incl. Trop. Dis. 2020, $26,1-11$. [CrossRef]

14. Lebing, W.; Remington, K.M.; Schreiner, C.; Paul, H.I. Properties of a New Intravenous Immunoglobulin (IGIV-C, 10\%) Produced by Virus Inactivation with Caprylate and Column Chromatography. Vox Sang. 2003, 84, 193-201. [CrossRef] [PubMed]

15. El-Ekiaby, M.; Vargas, M.; Sayed, M.; Gorgy, G.; Goubran, H.; Radosevic, M.; Burnouf, T. Minipool Caprylic Acid Fractionation of Plasma Using Disposable Equipment: A Practical Method to Enhance Immunoglobulin Supply in Developing Countries. PLoS Negl. Trop. Dis. 2015, 9, e0003501. [CrossRef] [PubMed]

16. Wu, Y.W.; Champagne, J.; Toueille, M.; Gantier, R.; Burnouf, T. Dedicated Removal of Immunoglobulin (Ig)A, IgM, and Factor (F)XI/Activated FXI from Human Plasma IgG. Transfusion 2014, 54, 169-178. [CrossRef] [PubMed]

17. Alonso, W.; Vandeberg, P.; Lang, J.; Yuziuk, J.; Silverstein, R.; Stokes, K.; McBride, D.; Cruz, M.; Burns, D.; Merritt, W.K.; et al Immune Globulin Subcutaneous, Human $20 \%$ Solution $\left(\right.$ Xembify $^{\circledR}$ ), a New High Concentration Immunoglobulin Product for Subcutaneous Administration. Biologicals 2020, 64, 34-40. [CrossRef]

18. Vandeberg, P.; Cruz, M.; Diez, J.M.; Merritt, W.K.; Santos, B.; Trukawinski, S.; Wellhouse, A.; Jose, M.; Willis, T. Production of Anti-SARS-CoV-2 Hyperimmune Globulin from Convalescent Plasma. Transfusion 2021, 61, 1705-1709. [CrossRef]

19. Cheng, J.H.; Wu, Y.W.; Wang, C.Y.; Wu, S.S.; Hong, C.L.; Chan, K.W.; Liao, L.X.; Cao, X.; Wang, B.; Burnouf, T. Process Steps for the Fractionation of Immunoglobulin (Ig) G Depleted of IgA, Isoagglutinins, and Devoid of in Vitro Thrombogenicity. Blood Transfus. 2021, 19, 467-478. [CrossRef]

20. Steinbuch, M.; Audran, R. The Isolation of IgG from Mammalian Sera with the Aid of Caprylic Acid. Arch. Biochem. Biophys. 1969, 134, 279-284. [CrossRef]

21. Parkkinen, J.; Rahola, A.; Von Bonsdorff, L.; Tölö, H.; Törmä, E. A Modified Caprylic Acid Method for Manufacturing Immunoglobulin G from Human Plasma with High Yield and Efficient Virus Clearance. Vox Sang. 2006, 90, 97-104. [CrossRef] [PubMed]

22. Lukačević, S.M.; Kurtović, T.; Balija, M.L.; Brgles, M.; Steinberger, S.; Marchetti-Deschmann, M.; Halassy, B. Quality-Related Properties of Equine Immunoglobulins Purified by Different Approaches. Toxins 2020, 12, 798. [CrossRef] [PubMed]

23. Morais, V.; Massaldi, H. A Model Mechanism for Protein Precipitation by Caprylic Acid: Application to Plasma Purification. Biotechnol. Appl. Biochem. 2012, 59, 50-54. [CrossRef] [PubMed]

24. Trapp, A.; Faude, A.; Hörold, N.; Schubert, S.; Faust, S.; Grob, T.; Schmidt, S. Multiple Functions of Caprylic Acid-Induced Impurity Precipitation for Process Intensification in Monoclonal Antibody Purification. J. Biotechnol. 2018, 279, 13-21. [CrossRef]

25. Brodsky, Y.; Zhang, C.; Yigzaw, Y.; Vedantham, G. Caprylic Acid Precipitation Method for Impurity Reduction: An Alternative to Conventional Chromatography for Monoclonal Antibody Purification. Biotechnol. Bioeng. 2012, 109, 2589-2598. [CrossRef] 
26. Yu, M.W.; Finlayson, J.S. Quantitative Determination of the Stabilizers Octanoic Acid and N-acetyl-dl-tryptophan in Human Albumin Products. J. Pharm. Sci. 1984, 73, 82-86. [CrossRef]

27. Athavale, M.; Fernandes, A.; Kaundinya, J.; Daftary, G. Validation of a Simple, Rapid and Cost Effective Method for the Estimation of Caprylic Acid and Sodium Caprylate from Biological Products Using NEFA-C Kit. Biologicals 2010, 38, 321-324. [CrossRef]

28. Validation of Analytical Procedures: Text and Methodology, ICH Q2 (R1). In Proceedings of the International Conference on Harmonization (ICH) of Technical Requirements for Registration of Pharmaceuticals for Human Use, Geneva, Switzerland, November 2005. Available online: https:/ / database.ich.org/sites/default/files/Q2\%28R1\%29\%20Guideline.pdf (accessed on 10 February 2022).

29. Saadati, N.; Abdullah, M.P.; Zakaria, Z.; Sany, S.B.T.; Rezayi, M.; Hassonizadeh, H. Limit of Detection and Limit of Quantification Development Procedures for Organochlorine Pesticides Analysis in Water and Sediment Matrices. Chem. Cent. J. $2013,7,1$. [CrossRef]

30. Şengül, Ü. Comparing Determination Methods of Detection and Quantification Limits for Aflatoxin Analysis in Hazelnut. J. Food Drug Anal. 2016, 24, 56-62. [CrossRef]

31. Sanagi, M.M.; Ling, S.L.; Nasir, Z.; Hermawan, D.; Wan Ibrahim, W.A.; Naim, A.A. Comparison of Signal-to-Noise, Blank Determination, and Linear Regression Methods for the Estimation of Detection and Quantification Limits for Volatile Organic Compounds by Gas Chromatography. J. AOAC Int. 2009, 92, 1833-1838. [CrossRef]

32. Shrivastava, A.; Gupta, V. Methods for the Determination of Limit of Detection and Limit of Quantitation of the Analytical Methods. Chron. Young Sci. 2011, 2, 21. [CrossRef]

33. Vander Heyden, Y.; Nijhuis, A.; Smeyers-Verbeke, J.; Vandeginste, B.G.M.; Massart, D.L. Guidance for Robustness/Ruggedness Tests in Method Validation. J. Pharm. Biomed. Anal. 2001, 24, 723-753. [CrossRef]

34. US Food and Drug Administration. Reviewer Guidance: Validation of Chromatographic Method; US Food and Drug Ad-Ministration: Rockville, MD, USA, 1994. 